Değini

\title{
Emek ve Temsil Ekseninde Günümüz Medyasında Kadınlar Sempozyumu'nun Ardından
}

\author{
Çăgla Kubilay \\ Ankara Üniversitesi Illetişim Fakültesi \\ Gazetecilik Bölümü
}

Ankara Üniversitesi İletişim Fakültesi ve ODTÜ Kuzey Kıbrıs Kampusunun işbirliğiyle düzenlenen "Emek ve Temsil Ekseninde Günümüz Medyasında Kadınlar Sempozyumu" 8-9 Mayıs 2014 tarihlerinde yapıldı. ODTÜ KKK Kültür ve Kongre Merkezi'nde gerçekleştirilen sempozyumun amacı, “emek süreçleri ve temsil sorunu çerçevesinde medyada kadınların var oluş biçimlerini irdeleyen bir bilimsel platform oluşturmak" olarak saptanmıştı. Bu bağlamda "medya sektöründe çalışan kadınların konumları ve sorunları", "medyada çalışan kadınlara yönelik yatay ve dikey ayrımcılık biçimleri", "medya sektöründeki cinsiyetçi yapılanma karşısında çözüm önerileri", "medyada kadınların temsil düzeyi ve biçimleri" ve "medyada kadın imgeleri" gibi temalar başta olmak üzere medya ve kadın konusunda çalışan bilim insanlarına çă̆rı yapılmıştı. Türkiye ve KKTC'nin 15 üniversitesinden 32 bilim insanının katıldığı sempozyumda, emek süreçleri ve temsil sorunu bağlamında medyada kadınların var oluş biçimleri çeşitli boyutlarıyla ele alındı. Sempozyumda "sinema ve toplumsal cinsiyet", "cinsellik ve beden politikaları", "popüler kültürde kadın temsilleri”, "kadına yönelik şiddet", "kadın emeği ve medya”, "yeni medyada kadın imgeleri", "reklam ve toplumsal cinsiyet" ve "medyada kadınlık halleri" başlıklı 8 oturumda toplam 28 sunuş yapıldı.

http://ilefdergisi.org/2014/1/1/

ilef dergisi · ilef journal • (c) 2014 • 1(1) • bahar/spring: 143-149 
İki gün süren sempozyum, Kampus Rektörü Prof. Dr. Turgut Tümer ve Sempozyum Düzenleme Kurulu Başkanları'ndan Doç. Dr. Özgür Erdur Baker'ın yaptıkları açılış konuşmalarıyla başladı. Açılış konuşmalarının ardından Gloria Bremer ve Maria Luisa Gambale'nin yönettikleri Sarabah adlı film gösterildi. 2011 yapımı film, Senegalli kadın şarkıcı ve aktivist Sister Fa'nın kendi ülkesinde kadın sünnetini engelleme mücadelesine odaklanıyordu. Film gösteriminden sonra Maria Luisa Gambale, kadın yönetmenlerin kadın konulu filmlerinin dağıtımını ele alan bir sunuş yaptı.

Öğleden sonra başlayan "Beyaz Perdeden Yansıyanlar: Sinema ve Toplumsal Cinsiyet" başlıklı ilk oturumun ilk bildirisini Selçuk Üniversitesi'nden Dr. Sinem Evren Yüksel sundu. "Komedi Filmlerinde Toplumsal Cinsiyet Kimliklerinin İnşası" başlıklı bildirisinde Yüksel, 2000 sonrası üretilen popüler komedi filmlerinden hareketle, komedinin ataerkil ideolojinin cinsiyet kodlarıyla ilişkilenme biçimine ve toplumsal cinsiyet kimliklerine dair egemen söylemlerin kırılmasında ya da yeniden üretilmesinde oynadığı role odaklandı. Yüksel, çözümlediği filmlerin önemli bir kısmında toplumsal cinsiyet ideolojisinin yeniden üretiminin baskın olduğunu, ancak zaman zaman kırılmaların da gözlemlendiğini ifade etti. Oturumun ikinci bildirisi ise Ankara Üniversitesi'nden Dr. Eren Yüksel'e aitti. Yüksel, Kadın yönetmenlerin 2000 sonrası çektiği minimalist nitelikli filmlerde erkek kimliğinin inşa ediliş biçimini sorunsallaştırdığı bildirisinde, erkekliğin sorgulanmasına ilişkin anlamların bu filmlerde dolaşıma sokulduğunu vurguladı. Yüksel, kadın yönetmenlerin filmlerinde kadınların baskı altına alınış biçimleri dile getirilirken erkekliğin de problemli bir alan olduğuna işaret edildiğini belirtti. Oturumun son konuşmasını Ankara Üniversitesi'nden Tolga Ulusoy yaptı. Hayao Miyazaki'nin filmleri aracılığıyla, animasyon dünyasındaki kadın karakterlerin çözümlenmesini ve toplumsal cinsiyetlendirilişlerini inceleyen Ulusoy, yönetmenin filmlerinin mevcut cinsiyet rejimine yönelik mücadelede önemli fikirler ortaya koyduğunu ifade etti. Ulusoy, özellikle de Disney animasyonları ile karşılaştırıldığında Miyazaki filmlerinin toplumsal cinsiyet ilişkilerinin sunumu açısından önemli bir alternatif olduğunu vurguladı.

İlk günün ikinci oturumunun teması, cinsellik ve beden politikalarıyd. Oturumun ilk sunuşunu yapan Atatürk Üniversitesi'nden Yard. Doç. Dr. Elif Küçük Durur ve Elif Taner, Türk sinemasında bekâretin temsilini fark1 yıllarda yapılmış beş film üzerinden analiz etti. Durur ve Taner, bekâretin temsili açısından farklı yıllarda yapılan filmlerde herhangi bir söylemsel değişim olmadığını, bekârete yönelik erkek egemen söylemin sürdüğünü iddia 
ettiler. Oturumun ikinci konuşması ise bana aitti. "İslâmi-Muhafazakâr Kadın Köşe Yazarlarının Perspektifinden Kürtaj Tartışması" başlıklı bildirimde, İslami kesimin kadın yazarlarının kürtaja ilişkin yaklaşımlarını, hem yasağı savunan İslami kesimin erkeklerine hem de "bedenim benimdir" anlayışını savunan kadınlara karşı yürüttükleri söylemsel mücadele düzleminde ele aldım. Üçüncü konuşmacı olan Ankara Üniversitesi’nden Dr. Deniz Sezgin ise "Medyada Kadın Sağlığı" başlıklı bildirisinde, yazılı basında kadın sağlığının yer alma biçimlerine odaklandı. Sezgin, ulusal basından çok sayıda gazeteyi incelediği çalışmasında kadınlara ilişkin sağlık haberlerinin sayısının sınırlı olduğuna ve bu haberlerin belirli konular etrafında çerçevelendiğine işaret etti. Oturumun son konuşmasını Bülent Ecevit Üniversitesi'nden Araş. Gör. Atilla Barutçu yaptı. “Masters E Johnson Cinsellik Araştırması'nın Gösteremedikleri: “Masters of Sex" Dizisi Üzerinden 1950'ler Amerikasında Kadınlık Halleri" başlıklı bildirisinde Barutçu, dizinin kadın karakterleri üzerinden annelik, cinsellik ve beden konularını feminist bir bakış açısıyla ele aldı.

Sempozyumun ikinci gününün sabahında iki paralel oturum yapıldı. İlk paralel oturumun teması, kadınlara ilişkin en yakıcı sorunlardan biri olan kadına yönelik şiddetti. Bu oturum, şiddet meselesini geniş bir perspektiften ele alan Prof. Dr. Güzin Yamaner'in "Köpekdişi (Kynodontas) Filminde Aile, Ebeveynliğin Sınırları ve Çocuk Eğitiminde Şiddet Olgularına Feminist Bir Bakış" başlıklı bildirisi ile başladı. Feminist eleştirel pedagoji, şiddet ve toplumsal cinsiyet çalışmaları literatüründen hareketle toplumsal cinsiyet hiyerarşileri bağlamında filmi analiz eden Yamaner, filmin ailenin çocuklar için güvenilir bir yer olup olmadığı, ebeveynliğin ve ebeveynlerin çocukları üzerindeki tasarrufunun sınırları gibi konuları tartışmaya açtığına işaret etti. Galatasaray Üniversitesi'nden Simge Süllü ise “Kadına Yönelik Şiddet Haberlerinde Etik: Sarai Sierra Örneği ve 'Diğerleri'” başlıklı bildirisinde doğrudan kadına yönelik şiddet meselesi üzerinde durdu. Türkiye'nin gündeminde önemli bir yer işgal eden Sierra cinayetine ilişkin haberler ile yine aynı dönemde yayımlanan diğer kadına yönelik şiddet haberlerini Hürriyet gazetesi üzerinden inceleyen Süllü, haberlerdeki etik ihlallere dikkat çekti. Oturumun son konuşmacısı Başkent Üniversitesi'nden Araş. Gör. Didem HekimoğluTunceli ise, kadına yönelik şiddet ve şiddeti önlemeye dönük kampanyalarla ilgili olarak Başkent Üniversitesi çalışanları ve öğrencileri üzerinde yürüttüğü araştırmanın sonuçlarını paylaştı.

Sabah yapılan ikinci paralel oturumda popüler kültürde kadın temsilleri tartışıldı. İlk konuşmayı yapan Yeditepe Üniversitesi'nden Dr. Özlem Akka- 
ya, “Kadın Yayıncıların Popüler Kültürde Değişen İmajları" başlıklı bildirisinde 1970'lerde ve 1980'lerde haftalık televizyon dergilerinin yayıncı kadınları temsil etme biçimlerini ele aldı. Akkaya, incelenen yıllarda televizyon dergilerinin yayıncı kadınları çoğunlukla ev kadını ve anne kimliklerini öne çıkararak temsil ettiğini; ancak 1980'lerde dönemin tüketimci değerleri yaygınlaştırma politikasına uygun olarak kadınların bireyselliklerinin de vurgulanmaya başlandığına işaret etti. Oturumun ikinci bildirisi, Ankara Üniversitesi'nden Araş. Gör. Emine Gülal ve Araş. Gör. Türker Şahin'e aitti. “Olmayan Kadının Adı: Nil Karaibrahimgil ve 'Modern Kadın' Şarkıları” başlıklı bildirilerinde Karaibrahimgil'in şarkılarını Lacancı psikanalizden hareketle çözümleyen Gülal ve Şahin, şarkıcının “özgür kız” imajı ve "modern, ideal kadın” göstereniyle tanındığını, ancak şarkılarında belirli anlamların yeniden üretildiğini belirttiler. Konuşmacılar, dolaşıma sokulan bu anlamların “özgür kız” imajının aksine "erkeğin tamamlayıcısı olma gayretindeki modern kadın"a işaret ettiğini ileri sürdü. Oturumun üçüncü konuşması, uzun süredir Türk televizyonlarında yayımlanan Arçelik reklamlarındaki toplumsal cinsiyet ilişkileri hakkındaydı. Ankara Üniversitesi’nden Zeynep Saygın Sarbay, “Her Genç Robotun Hayali: Arçelik Reklamlarında Kullanılan Animasyonların Kadın ve Erkek Temsilleri" başlığını taşıyan bildirisinde, reklamlarda yer alan Çeliknaz'ın bir robot olarak "ideal kadın” temsiline hizmet ediş biçimini, evlilikteki rolü ile hetero-normatif bir yapıda bir öteki olarak yer alışını değerlendirdi. ODTÜ'den Hanen Çiftdoğan, oturumun son konuşmacısıydı. Çiftdoğan, konuşmasında, 2011-2012 futbol sezonunda seyircisiz oynama cezası olan maçlara kadınların alınmasına ilişkin kararı merkeze alarak, bu uygulama öncesi ve sonrasında medyada futbolla ilişkilendirilen kadın imajındaki değişimler üzerinde durdu.

Sempozyumun ikinci gününde öğleden sonra dört paralel oturum yapıldı. Paralel oturumların birincisi, sempozyumun temel eksenlerinden biri olan emek süreçleri üzerineydi. "Kadın Emeği ve Medya” başlıklı oturumda medyada kadın çalışanların durumu ve sorunlarına odaklanan bildirilerden ilki, Çukurova Üniversitesi'nden Doç. Dr. Nüket Elpeze-Ergeç ve Yard. Doç. Dr. Tülay Görü-Doğan'a aitti. “Medyada Emek Bağlamında Kadının Varoluşu" başlıklı bildiride, yerel medyada çalışan kadınların koşulları ve toplumsal cinsiyet bağlamında yaşadıkları sorunlar Adana ili örneği üzerinden değerlendirildi. Kadın gazetecilerin kendilerine "gazeteci" demekten çekinmesi, bunun yerine "medya emekçisi, basın emekçisi" sözcüklerini tercih ettiklerinin bulgulanması bildirinin dikkat çeken sonuçlarından biriydi. Oturumun ikinci bildirisi, Galatasaray Üniversitesi'nden Yard. Doç. Dr. Gülsün Güvenli 
ve Araş. Gör. Melda Sunar’ın ortak çalışmaları olan “Dizi Sektöründe Çalışan Kadınlar" başlığını taşıyordu. Bildiriyi sunan Güvenli, dizi sektöründeki erkek egemen yapılanmadan hareketle, kadınların bu alanda işgücüne katılım biçimlerini 49 yerli dizinin jenerikleri temelinde değerlendirdiklerini ifade etti. Güvenli, kadınların dizi sektöründe yer almalarına rağmen yönetmenlik, yapımcılık, teknik kısım gibi bazı alanların "erkek alanı" olarak görülmeye devam ettiğini ve kadınların bu alanda var oluşlarının sınırlı olduğunu belirterek dizi sektöründeki yatay ayrımcılık biçimlerine dikkat çekti. Üçüncü bildiri, Işık Üniversitesi'nden Yard. Doç. Dr. Nalan Büker'e aitti. Televizyon sektöründe çalışan kadınların sorunlarını ele alan Büker, kadınların işgücüne katılımında 1990'ların oranlarına ulaşmaya çalıştığını vurgulayarak bu sektörde toplumsal cinsiyet eşitliğinin sağlanması gerektiğini söyledi. Kadın ve erkeklerin eşit düzeyde temsilinin önemine dikkat çeken Büker, eşitliğin sağlanabilmesi için ayrımcılıkla mücadele kanununun geliştirilmesi, RTÜK ve RATEM Akademi'nin ortak çalıştay düzenlemesi, İŞKUR ve sektör işbirliği ile yürütülen politikaların revize edilmesi gibi çeşitli önerilerde bulundu. Oturumun son konuşmasını ise Kastamonu Üniversitesi'nden Araş. Gör. Şeyma Balcı yaptı. Balcı, "Yerel Medyada Kadın Gazeteciler: Kastamonu Örneği” başlıklı bildirisiyle Kastamonu'da yayımlanan 16 gazetede çalışan 15 kadın gazeteci ile yaptığı anket ve derinlemesine görüşme teknikleriyle elde ettiği sonuçları paylaştı.

"Kadın Emeği ve Medya" oturumuna paralel olan oturum, "Reklam ve Toplumsal Cinsiyet" başlığını taşıyordu. Lefke Avrupa Üniversitesi'nden Dr. Esra Aydın-Kılıç, "cam tavan sendromu"nu merkeze alarak kadınların toplumsal rollerinin televizyon reklamlarında kurgulanma biçimlerine dair bir değerlendirme yaptı. Oturumda ikinci olarak Ankara Üniversitesi'nden Araş. Gör. Esra İnce ve Dr. Deniz Sezgin, toplumsal cinsiyet ekseninde televizyon reklamlarında kadın imgesinin kullanımına ilişkin bir sunum yaptı. Atatürk Üniversitesi'nden Tolgahan Ünal, kadın ve erkek dergilerindeki reklamlar üzerinden bir toplumsal cinsiyet analizi yaparken, ODTÜ KKK'dan Deniz Mat Artun ise 1970-2010 yılları arasında yazılı ve görsel medyada yayımlanan reklamlarda, kadınların temsilinde yaşanan değişimi ve bu değişimin nedenlerini ele aldi.

Sempozyumun son iki paralel oturumunun ilkinde, "Medyada Kadınlık Halleri" tartışıldı. Oturumda ilk olarak Mersin Üniversitesi'nden Yard. Doç. Dr. Aslıhan Ardıç Çobaner, "Medyada Kadına Yönelik Stereotipler: 'Sigara İçen Kadın İmgesi' " başlıklı sunuşunu yaptı. Medyada kadınlık rolleri- 
nin belirli imgeler ve yaşam tarzları doğrultusunda sunulduğunu, bunlardan birinin de kadının cinsel kimliği olduğunu belirten Ardıç-Çobaner, Türk basınından seçtiği dört gazetedeki sigarayla ilgili haberlerde ve yazılarda kullanılan görsellerde "sigara içen kadın" imgesine odaklandı. Konuşmasında, "sigara içen kadın" görsellerinin basında sıklıkla kullanıldığını ve söz konusu görsellerde kadına yönelik cinsiyetçi bakış açısının "özgürlük, incelik, çekicilik ve arzu edilir olma" stereotipleri yoluyla sürdürüldüğünü ifade etti. Oturumun ikinci konuşmasını Başkent Üniversitesi'nden Öğr. Gör. Nesli Tuğban Yaban yaptı. Medya sektöründe çalışan kadınların, kadın kimlikleri nedeniyle emeklerinin görmezden gelindiğini ifade eden Yaban, kadın emeğinin kayboluşunu medyada yer alan kadın imgeleriyle ilişkisi bağlamında tartışı. Sanat yapıtlarında temsil edilen kadın imgesi ile medyadaki kadın temsilleri arasında kurduğu bağlantıyla dikkat çeken konuşmasında Yaban, medyada dolaşıma giren kadın imgeleri nedeniyle, üretim aşamasında olan kadınların görmezden gelinerek kadınların bir tür "vitrin" olarak sergilendiğine işaret etti. Oturumun üçüncü ve son konuşması ise yine Başkent Üniversitesi'nden Araş. Gör. Sevil Bal'a aitti. "Annelik Olgusunun Yeniden Üretimi Sürecinde Reklamları Konumlandırmak: Anneler Günü Kampanyaları İçerikli İnternet Reklamları Üzerine Eleştirel Bir Değerlendirme" başlıklı bildirisinde Bal, son beş yılda farklı sektörlerde faaliyet gösteren kurumların internette yayımlanan anneler günü temalı ilan ve broşürlerindeki annelik mitini tartıştı.

Sempozyumun nihai oturumu, iletişim çalışmaları alanında önemli bir yer tutan yeni medyaya ilişkindi. Üç konuşmanın yapıldığı oturumda ilk olarak Ankara Üniversitesi'nden Araş. Gör. İlkin Esen Yıldırım "Toplumsal Cinsiyet Üzerinden 'Reklamdaki Kadın'ı Okumak: Morhipo Örneği”' başl1ğını taşıyan bildirisinde internet alışveriş sitelerinden Morhipo'nun televizyonda yayımlanmış reklamlarındaki kadın imajını ele aldı. Yıldırım, sunuşunda Morhipo reklamlarında sunulan "tüketmek için rekabet eden kadın" imgesinin altını çizdi. İkinci konuşmacı Gazi Üniversitesi'nden Dr. Pelin Öztürk-Göçmen de Yıldırım'a benzer şekilde yeni medya reklamlarındaki kadın imgesine odaklandı. Öztürk-Göçmen, Facebook'ta yer alan reklamlar üzerinden anlamın yeniden üretimi ve temsil kavramları ekseninde kadın imgesinin medyada dönüştürülme biçimi üzerinde durdu. Gazi Üniversitesi'nden Kamil Mingü, “THY Ruj Yönetmeliği ve Kamusal Alan Kapsamında Yer Alan Yeni Medyadaki Tepkilerin Etkisi" başlıklı sunuşu ile oturumun son konuşmacısı oldu. THY'nin kadın kabin memurlarının kırmızı ruj kullanmasının yasaklanmasını kamusal alanda ataerkil örüntülerin sürdürülmesi olarak nitelendiren Mingü, bu çerçevede haberlere yapılan okuyucu yorumlarını ele 
aldı. Söz konusu yasağa internet ortamında gelen tepkilerin yasağın kaldırılmasında etkili olduğunu ifade eden Mingü, buradan hareketle internetin bir toplumsal güç olarak önemine dikkat çekti.

İletişim, güzel sanatlar ve kadın çalışmaları gibi farklı ama birbiriyle kesişen alanlardan gelen araştırmacıları buluşturan sempozyum, ODTÜ KKK'nın misafirperverliği ile oldukça sıcak bir ortamda yapıldı. Kısa bir sürede hayata geçirilen, yoğun ve titiz bir çalışmanın ürünü olan sempozyumda hemen hemen hiçbir aksaklık yaşanmadı. Gerek medya, gerekse kadınlar üzerindeki baskıların neoliberal ve neomuhafazakâr politikalar doğrultusunda artırıldığı bir dönemde, bu iki sorunlu alanı bir arada ele alan bilimsel toplantıların sürdürülmesi gerekliliği sempozyumda ortaya çıkan en önemli sonuç oldu. 